\title{
Geomagnetic Variations Associated with Strong Earthquakes in Yunnan Area
}

\author{
Xiuyi Yao1, Zhisheng Feng2², Yuntian Teng³ , Yunhui Wang', Qiuyue Zheng1 \\ ${ }^{1}$ Yunnan Earthquake Agency, Kunming, China \\ ${ }^{2}$ Jiangsu Earthquake Agency, Nanjing, China \\ ${ }^{3}$ Institute of Geophysics, China Earthquake Administration, Beijing, China \\ Email: ^fengzs2001@sohu.com
}

How to cite this paper: Yao, X.Y., Feng, Z.S., Teng, Y.T., Wang, Y.H. and Zheng, Q.Y. (2017) Geomagnetic Variations Associated with Strong Earthquakes in Yunnan Area. Open Journal of Earthquake Research, 6, 228-237.

https://doi.org/10.4236/ojer.2017.64015

Received: October 22, 2017

Accepted: November 27, 2017

Published: November 30, 2017

Copyright $\odot 2017$ by authors and Scientific Research Publishing Inc. This work is licensed under the Creative Commons Attribution International License (CC BY 4.0).

http://creativecommons.org/licenses/by/4.0/

\begin{abstract}
In order to find geomagnetic anomalies associated with $M_{\mathrm{s}} \geq 6.0$ strong earthquakes in Yunnan area, geomagnetic harmonic wave amplitude ratios with $Z, H$ and $D$ components in TCH, THJ, CHX and YOS stations were analyzed. It was found that geomagnetic amplitude ratio of Yzhx experienced a trend of decrease and increase before most of strong earthquakes. Moreover, these variations in different periods were inconsistent and no similar changes appeared for Yzhy, which may relate to fault-zone conductivity variation and seismogenic structure.
\end{abstract}

\section{Keywords}

Earthquake Precursor, Geomagnetic Amplitude Ratio, Yunnan Area

\section{Introduction}

It has been reported that electromagnetic precursors in association with a lot of large earthquakes. Observations both serendipitous and planned have encompassed a wide variety of measurements of electric and magnetic fields [1] [2] [3] [4]. Merzer and Klemperer [5] proposed a quasi-static model, in which the conductive fault zone acts as an antenna to couple with the external geomagnetic field to generate the observed geomagnetic anomalies [6]. Precursory changes in fault-zone conductivity lead to precursory changes in observed geomagnetic field. The detection of geomagnetic perturbation prior to fault ruptures has been proposed as an effective method for monitoring crustal activities [7] [8] [9]. There have been many reports on geomagnetic changes associated with earthquakes and several methodologies are proposed such as polarization analysis [10] [11] [12] [13], principal component analysis (PCA) [14] [15] [16], Fractal 
analysis [17] [18] and Low-point displacement analysis [19] [20] [21]. Feng et al. [22] [23] [24] proposed a method named geomagnetic harmonic wave amplitude ratio analysis (we call it geomagnetic amplitude ratio analysis for short in this paper) to obtain electromagnetic emissions as a precursor to an earthquake and a lot of studies were reported [25] [26] [27] [28]. In this paper, we also use this method to analyze geomagnetic variations which may associate with strong earthquakes in Yunnan area.

Yunnan province is located in the southeast margin of Tibetan Plateau. Due to long-term extrusion between Eurasian plate and Indian Ocean plate, the geologic structure of Yunnan area is complicated and seismicity is active [29]. Some statistical results have showed that, 333 earthquakes with $M_{\mathrm{s}} \geq 5.0$ happened in Yunnan area in 20th century and one earthquake with $M_{\mathrm{s}} \geq 6.0$ occurred in a year on average [30]. Therefore, it is necessary to analyze the relation between magnetic anomalies and seismicity.

In this paper, we applied geomagnetic amplitude ratio analysis to historical geomagnetic data observed in Yunnan and try to find some significant precursory effect for historical earthquakes of $M_{\mathrm{s}} \geq 6.0$ in Yunnan area from 1990 to 2000 .

\section{Geomagnetic Data and Earthquakes}

There were 4 geomagnetic stations in Yunnan area from 1990 to 2000, they were Tengchong (TCH), Tonghai (THJ), Chuxiong (CHX) and Yongsheng (YOS) stations. CB-3 magnetometer was installed at every observatory and three geomagnetic components of $\mathrm{D} / \mathrm{H} / \mathrm{Z}$ were observed ( $H$ : NS component, $D$ : EW component and $Z$ : vertical component). Geomagnetic data from 1990 to 2000 was utilized for this analysis and earthquakes whose epicenter distance less than $300 \mathrm{~km}$ for $M_{\mathrm{s}} \geq 6.0$ and epicenter distance less than $400 \mathrm{~km}$ for $M_{\mathrm{s}} \geq 7.0$ were selected. The distribution of stations is given in Figure 1 and earthquakes selected are also plotted. Table 1 lists detail information of earthquakes we used. The nearest earthquake is Yaoan $M_{s} 6.5$ earthquake which happened in 15 January 2000, 70 $\mathrm{km}$ from CHX station. And the largest earthquake with magnitude $M_{\mathrm{s}} 7.3$ occurred in 1996, $347 \mathrm{~km}$ from TCH station.

Table 1. List of earthquakes $M_{\mathrm{s}} \geq 6.0$ within certain epicenter distance during 1990-2000.

\begin{tabular}{|c|c|c|c|c|c|c|c|c|c|}
\hline \multirow{2}{*}{ NO. } & \multirow{2}{*}{ Date } & \multirow{2}{*}{ Latitude } & \multirow{2}{*}{ Longitude } & \multirow{2}{*}{$\begin{array}{l}\text { Magnitude } \\
\left(M_{\mathrm{s}}\right)\end{array}$} & \multirow{2}{*}{$\begin{array}{c}\text { Depth } \\
(\mathrm{km})\end{array}$} & \multicolumn{4}{|c|}{ Epicentral distance $(\mathrm{km})$} \\
\hline & & & & & & $\mathrm{TCH}$ & THJ & CHX & YOS \\
\hline 1 & $1992-04-23$ & $22.6^{\circ} \mathrm{N}$ & $99.0^{\circ} \mathrm{E}$ & 6.9 & 31 & 310 & 418 & 372 & 481 \\
\hline 2 & $1993-01-27$ & $23.1^{\circ} \mathrm{N}$ & $101.1^{\circ} \mathrm{E}$ & 6.3 & 14 & 339 & 202 & 217 & 391 \\
\hline 3 & $1995-07-12$ & $22.0^{\circ} \mathrm{N}$ & $99.3^{\circ} \mathrm{E}$ & 7.3 & 9 & 347 & 424 & 405 & 534 \\
\hline 4 & $1995-10-24$ & $25.9^{\circ} \mathrm{N}$ & $102.2^{\circ} \mathrm{E}$ & 6.5 & 15 & 382 & 208 & 120 & 160 \\
\hline 5 & $1996-02-03$ & $27.2^{\circ} \mathrm{N}$ & $100.3^{\circ} \mathrm{E}$ & 7.0 & 10 & 300 & 424 & 273 & 83 \\
\hline 6 & $1998-11-20$ & $27.3^{\circ} \mathrm{N}$ & $100.9^{\circ} \mathrm{E}$ & 6.2 & 10 & 347 & 402 & 263 & 79 \\
\hline 7 & 2000-01-15 & $25.5^{\circ} \mathrm{N}$ & $101.1^{\circ} \mathrm{E}$ & 6.5 & 30 & 265 & 228 & 70 & 126 \\
\hline
\end{tabular}




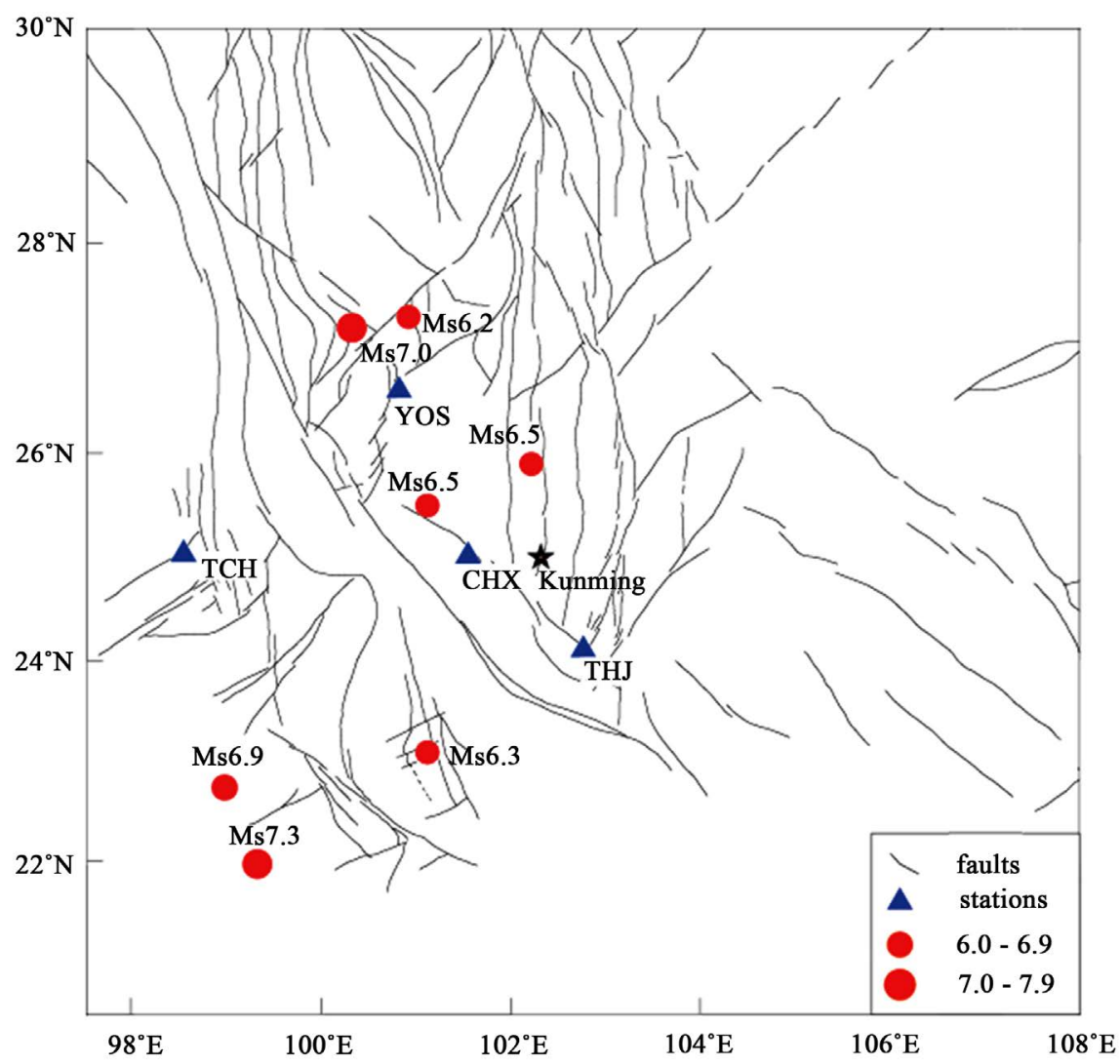

Figure 1. Distribution of geomagnetic stations and earthquakes from 1992 to 2000. Red dots indicate earthquakes selected, blue triangles represent geomagnetic stations in Yunnan area.

\section{Geomagnetic Amplitude Ratio Analysis}

If the structure of underground is homogeneous transversely, geomagnetic field changes with frequency as below [31]:

$$
\left\{\begin{array}{l}
\frac{Z(\omega)}{H_{x}(\omega)}=\frac{Z(\omega)}{H_{y}(\omega)}=i \frac{\lambda}{\theta} \\
\theta^{2}=\sigma \mu \omega i+\lambda^{2}
\end{array}\right.
$$

where the subscript $\mathrm{x}$ indicates NS orientation of coordinate system, $y$ represents EW and $\omega$ is circular frequency, $\lambda$ is wave number of geomagnetic field and we regard it as a constant in this paper, $\mu$ and $\sigma$ represent permeability and conductivity. $Z(\omega), H_{\mathrm{x}}(\omega)$ and $H_{\mathrm{y}}(\omega)$ indicate spectral amplitudes of $Z$, $H$ and $D$, respectively. Each element in Equation (1) is a complex number as a function of frequency.

Geomagnetic amplitude ratios were defined as below:

$$
Y_{Z H_{x}}=\left|\frac{Z(\omega)}{H_{x}(\omega)}\right|, \quad Y_{Z H_{y}}=\left|\frac{Z(\omega)}{H_{y}(\omega)}\right|
$$

Recorded geomagnetic field consists of internal and external source field, and it is difficult to separate them. Normal geomagnetic field consists of external 
field and induced field for the normal horizontal-layer earth. The abnormal field only consists of the contribution of changing inhomogeneous transversely structures. When external source field is uniform and the horizontal-layer structure in the earth is electric homogeneous transversely, the vertical component will not be observed on the surface of earth. Therefore, $Z(\omega)$ which comes from normal field for uniform source is close to 0 [32]. However, the horizontal layers in the earth are electric inhomogeneous transversely and the source field is non-uniform actually. Therefore, the geomagnetic amplitude ratios of Yzhx and Yzhy could describe the changes of electric inhomogeneous transversely structures underground which are usually embodies in the changes of conductivity.

A lot of studies showed that geo-resistivity changed mostly decrease prior to earthquakes [33]. According to Equation (1), geomagnetic amplitude ratios of Yzhx and Yzhy are proportion to resistivity, so they should have similar changes. Feng and other researchers [22] [23] [24] [25] [26] found that most earthquakes occurred when geomagnetic amplitude ratios increase after decrease like resistivity expected. In this paper, we digitized every magnetogram one point per minute from 1990 to 2000 which means the sampling rate is $1 \mathrm{~min}$. The waveforms of three components $(D / H / Z)$ during each interval of 1200 minutes were subjected to maximum likelihood spectrum analysis. Then, we calculated geomagnetic amplitude ratios of Yzhx and Yzhy and analyzed their variations with earthquakes. In order to remove annual variation of geomagnetic field, Yzhx and Yzhy were dealt with 12-month-running.

\section{Results Analysis}

\subsection{Variation of Geomagnetic Amplitude Ratios}

According to Equation (2), geomagnetic amplitude ratios in period of 13, 20, 31, 49, 78, 113, 157 and 204 minutes of TCH, THJ, CHX and YOS stations were calculated. Figures 2-5 show temporal variations of Yzhx and Yzhy of each

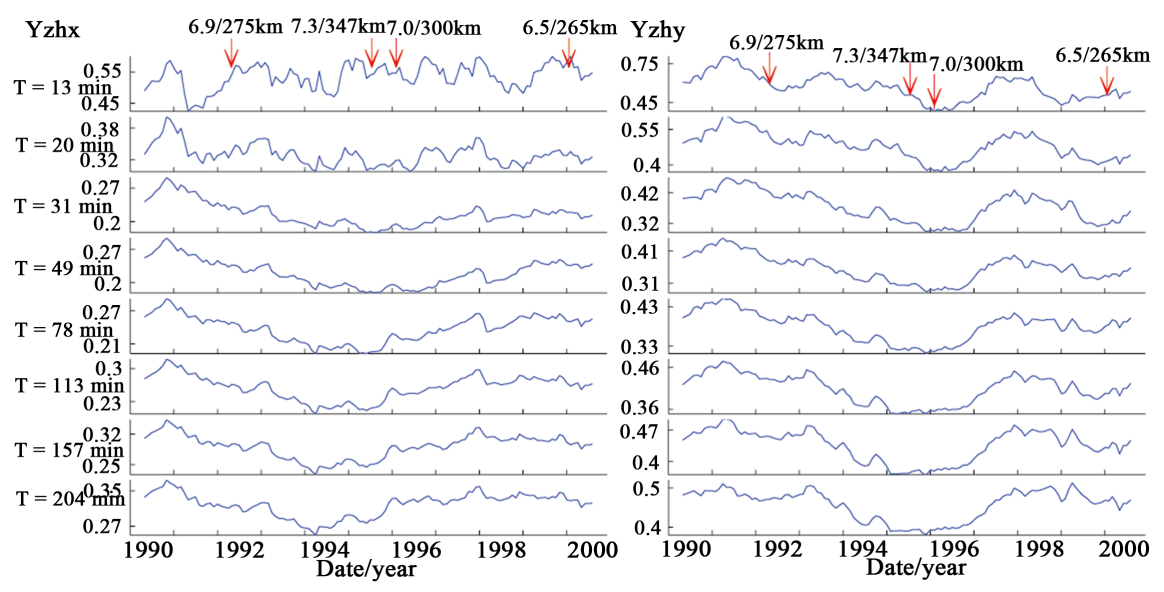

Figure 2. Temporal variations of Yzhx and Yzhy in different periods at TCH station from 1990 to 2000 and corresponding earthquakes. The vertical arrows indicate earthquakes occurrence date, magnitudes and epicentral distances also be marked, the same below. 

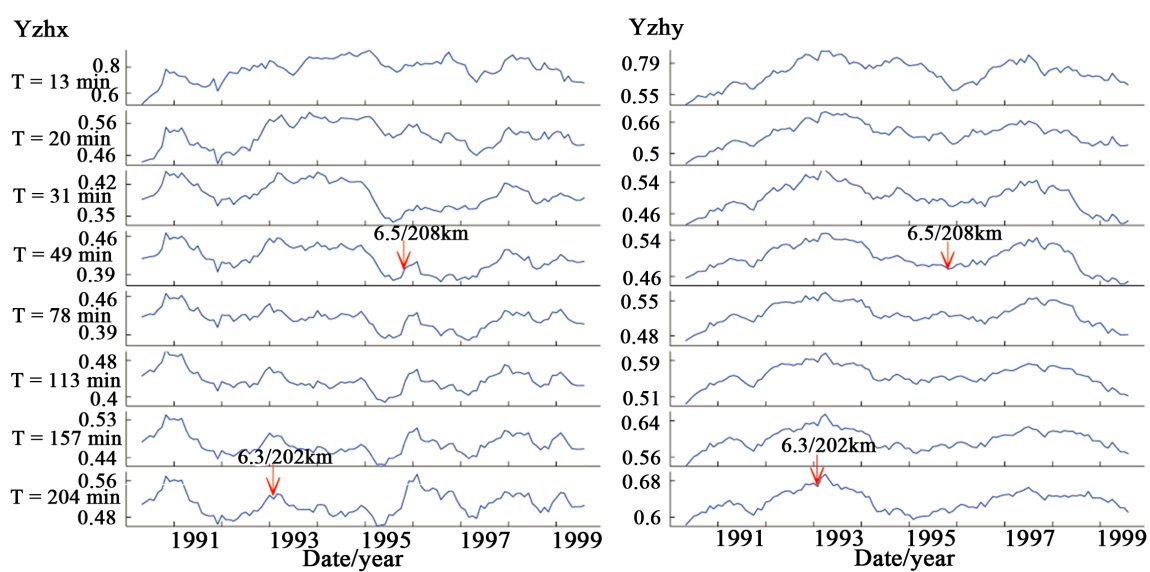

Figure 3. Temporal variations of Yzhx and Yzhy in different periods at THJ station from 1990 to 1999 and corresponding earthquakes.
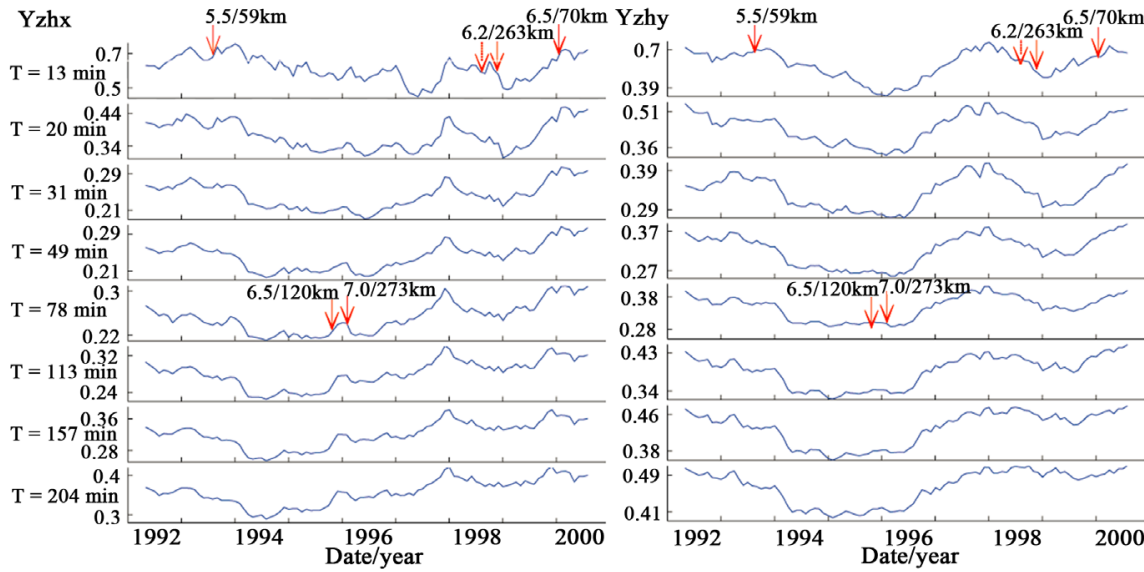

Figure 4. Temporal variations of Yzhx and Yzhy in different periods at CHX station from 1992 to 2000 and corresponding earthquakes.

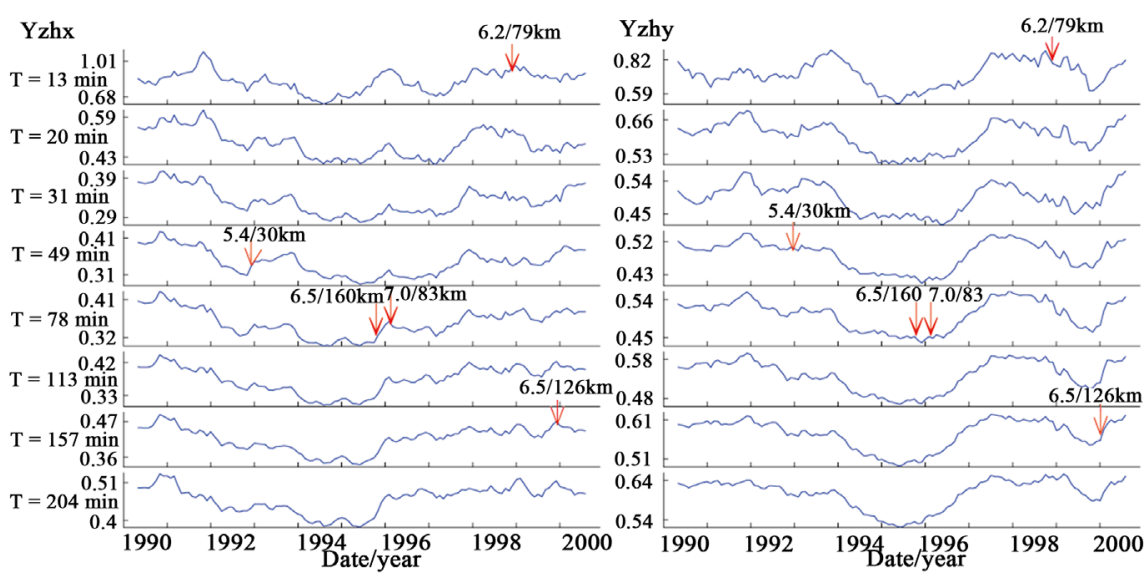

Figure 5. Temporal variations of Yzhx and Yzhy in different periods at YOS station from 1990 to 2000 and corresponding earthquakes.

station in these periods from 1990 to 2000, respectively. Furthermore, earthquakes (some earthquakes with $M_{s} \geq 5.0$ within very small epicentral distance) 
were marked with vertical arrows.

In general, the temporal variations of Yzhx and Yzhy in each period are similar especially in longer periods. That means the changes of earth conductivity in different depth were semblable especially in deeper layers. Therefore, an obvious inconsistency, which related to changes of local crust conductivity, may have relevant with earthquakes.

Temporal variations of Yzhx and Yzhy are different. First of all, Yzhy is more stable and consistent than Yzhx. Because most fault strikes in Yunnan area are north-south approximate, which means the conductivity of north-south is more changeable. And then, almost Yzhx and Yzhy in each period are small than 1.0, and reach maximum in period of 13 to $78 \mathrm{~min}$ then decrease with the increase of period. Lastly, geomagnetic amplitude ratios of YOS station are the largest for same period, followed by THJ, CHX and TCH. Yzhy is greater than Yzhx because the amplitudes of $H \mathrm{x}$ come from external geomagnetic field are greater than those of $H y$.

\subsection{Earthquake Cases Analysis}

Previous researches showed that geomagnetic amplitude ratios decrease prior to earthquakes, and most earthquakes occurred in the process of recovery [23] [24].

Figure 2 shows temporary variations of Yzhx and Yzhy at TCH station and corresponding earthquakes. It is clear that Yzhx in periods of $13 \mathrm{~min}$ and $20 \mathrm{~min}$ are inconsistent with other periods, especially those prior to strong earthquakes of $M_{s} 6.9$ and $M_{s} 6.5$. Refer to previous study results, we think the decrease of Yzhx last for more than 1 year may relate to earthquakes, which means the shallow crust conductivity changed before earthquakes. And earthquakes happened in the process of recovery or after that. However, these changes in Yzhy are nonexistent, which may relate to the rupture direction of fault or focal mechanism.

Figure 3 shows temporary variations of Yzhx and Yzhy at THJ station. All earthquakes happened in the process of recovery after decrease of Yzhx, but not all those decreasing situations have corresponding earthquakes. Yzhx decreased at the beginning of 1991 and return to normal at the end of 1992 and then earthquake with $M_{s} 6.3$ occurred in 27 January 1993. The longer periods the decrease process is more noticeable. Similarly, later earthquake with $M_{\mathrm{s}} 6.5$ also happened during the process of Yzhx increases at the end of 1995, which decreases at the beginning of 1995. Yzhx exceeds normal value when periods are more than $78 \mathrm{~min}$, while they are still below normal in other periods after increase. The process of down and up of Yzhx with inconsistency in different periods is more like precursors to earthquakes.

Figure 4 shows temporary changes of Yzhx and Yzhy at CHX station. Most earthquakes also happened in the process of increase or after that with inconsistency in different periods. Because the magnitude of $M_{s} 5.5$ happened in $14 \mathrm{Au}$ gust 1993 is small, the decreasing amplitudes in Yzhx are small and only exist in 
periods that lower than 49 min and just last 5 months. In addition, a process of down and up of Yzhx exist in periods of $13 \mathrm{~min}$ and $20 \mathrm{~min}$ in 1997 and 1999 then earthquakes with $M_{s} 6.2$ and $M_{s} 6.5$ follow. Time interval between anomaly ending and $M_{\mathrm{s}} 6.2$ earthquake occurrence seems too long compared with other earthquake cases. We consult the earthquake catalogue and find that 3 foreshocks with $M_{s} \geq 5.0$ happened before the main shock of $M_{s} 6.2$, and we mark them with dotted vertical arrows.

Figure 5 gives temporary variations of Yzhx and Yzhy at YOS station. The same as previous earthquake cases, most earthquakes occurred during the increase of geomagnetic amplitude ratios Yzhx after decrease. Moreover, the precursory variations of Yzhy to $M_{s} 6.2$ earthquake happened in 20 November 1998 and $M_{s} 6.5$ earthquake occurred in 15 January 2000 are more obvious than that of Yzhx.

\section{Conclusions}

Geomagnetic amplitude ratios in periods of 13, 20, 31, 49, 78, 113, 157 and 204 minutes of TCH, THJ, CHX and YOS stations in Yunnan area were obtained. Normally, the temporal variations of Yzhx or Yzhy in all periods are similar especially in longer periods. While, Yzhy is more stable and consistent, which means the underground conductivity of EW in Yunnan area is more stable and may relate to local geological structure of this area.

Significant decrease of Yzhx or Yzhy was found before nearby earthquakes during the whole analyzed time, and most of them happened during the process of recover to normal or after that. As other research results, we also found that the greater the anomalous amplitude, the greater the magnitude for similar epicentral distance. Take Yzhx in TCH station for example, $M_{s} 6.9$ earthquake happened in 23 April 1992 and $M_{s} 6.5$ earthquake occurred in 15 January 2000 with epicentral distance of $275 \mathrm{~km}$ and $265 \mathrm{~km}$ respectively. The anomalous amplitude of Yzhx before $M_{s} 6.9$ earthquake reaches $28 \%$, while that before $M_{s} 6.5$ earthquake is only $19 \%$. The specific relation between the anomalous amplitude and earthquake magnitude needs further study in the case of enough statistical samples.

\section{Discussion}

Moreover, $\mathrm{Du}$ [34] [35], Zheng [36] and Zhu [37] have found that the distribution of abnormal geo-resistivity stations and anomalous amplitudes prior to earthquakes were related to fault parameters (like strike or dip) and focal mechanism, especially the direction of principal compressive stress axis. The prominent changes occur in the component whose direction is perpendicular or nearly perpendicular to principal compressive orientation, and the abnormal geo-resistivity stations were almost along the orientation which perpendicular to the rupture direction of fault. Geo-resistivity change leads to the variation of geomagnetic amplitude ratios Yzhx and Yzhy, so the distribution of abnormal 
geomagnetic stations and anomalous amplitudes of Yzhx and Yzhy may also be related to fault parameters and focal mechanism. Therefore, not all geomagnetic stations can record precursory electromagnetic emissions signals usually. Fortunately, significant precursory effects were found for most of earthquakes in this paper, and it's necessary to study the detail relation between geomagnetic amplitude ratios and fault parameters or focal mechanism in further research.

\section{Acknowledgements}

This research was financially supported by project of Science for Earthquake Resilience (XH182501Y).

\section{References}

[1] Rikitake, T. (1976) Geomagnetic and Geoelectric Effects in Earthquake Prediction. Elsevier Press, Amsterdam.

[2] Mogi, K. (1985) Geoelectricity and Geomagnetism in Earthquake Prediction. Academic Press, Tokyo.

[3] Parrot, M. and Johnston M. (1989) Seismo-Electromagnetic Effects. Physics of the Earth and Planetary Interiors, 57, 8.

[4] Park, S.K., Johnston, M.J.S., Madden, T.R., Morgan, F.D. and Morrison, H.F. (1993) Electromagnetic Precursors to Earthquake in the ULF Band: A Review of Observations and Mechanism. Review of Geophysics, 31, 117-132. https://doi.org/10.1029/93RG00820

[5] Merzer, M. and Klemperer, S.L. (1997) Modeling Low-Frequency Magnetic-Field Precursors to the Loma Prieta Earthquake with a Precursory Increase in Fault-Zone Conductivity. Pure and Applied Geophysics, 150, 217-248. https://doi.org/10.1007/s000240050074

[6] Robert, J.J., Duba, A.G., Mathez, E.A., Shankland, T.J. and Kinzler, R. (1999) Carbon-Enhanced Electrical Conductivity During Fracture of Rocks. Journal of Geophysical Research: Solid Earth, 104, 737-747. https://doi.org/10.1029/1998JB900032

[7] Sarlis, N. and Varotsos, P. (2002) Magnetic Field near the Outcrop of An Almost Horizontal Conductive Sheet. Journal of Geodynamics, 33, 463-476. https://doi.org/10.1016/S0264-3707(02)00008-X

[8] Han, P., Hattori, K., Huang, Q., Hirano, T., Ishiguro, Y., Yoshino, C. and Febriani, F. (2011) Evaluation of ULF Electromagnetic Phenomena Associated with the 2000 Izu Island Earthquake Swarm by Wavelet Transform Analysis. Natural Hazards and Earth System Sciences, 11, 965-970. https://doi.org/10.5194/nhess-11-965-2011

[9] Hattori, K., Han, P., Yoshino, C., Febriani, F., Yamaguchi, H. and Chen, C.H. (2012) Investigation of ULF Seismo-Magnetic Phenomena in Kanto, Japan during 2000-2010: Case Studies and Statistical Studies. Surveys in Geophysics, 34, 293-316. https://doi.org/10.1007/s10712-012-9215-X

[10] Hayakawa, M., Kawate, R., Molchanov, O.A. and Yumoto, K. (1996) Results of Ultra-Low-Frequency Magnetic Field Measurements during the Guam Earthquake of 8 August 1993. Geophysical Research Letters, 23, 241-244. https://doi.org/10.1029/95GL02863

[11] Hattori, K. (2004) ULF Geomagnetic Changes Associated with Large Earthquakes. Terrestrial, Atmospheric and Oceanic Sciences, 15, 329-360. https://doi.org/10.3319/TAO.2004.15.3.329(EP) 
[12] Li, J., Li, Q., Yang, D., Wang, X., Hong, D. and He, K. (2011) Principal Component Analysis of Geomagnetic Data for the Panzhihua Earthquake $\left(\mathrm{M}_{\mathrm{s}} 6.1\right)$ in August 2008. Data Science Journal, 10, 130-138. https://doi.org/10.2481/dsj.IAGA-20

[13] Li, Q., Yang, X. and Cai, S. (2015) Case Study of Applying Polarization Method to Geomagnetic Array Data. Technology for Earthquake Disaster Prevention, 10, 412-417.

[14] Uyeda, S., Hayakawa, M., Nagao, T., Molchanov, O., Hattori, K., Orihara, Y., Gotoh, K., Akinaga, Y. and Tanaka, H. (2002) Electric and Magnetic Phenomena Observed before the Volcano-seismic Activity in 2000 in the Izu Island Region, Japan. Proceedings of the National Academy of Sciences of the United States of America, 99, 7352-7355. https://doi.org/10.1073/pnas.072208499

[15] Serita, A., Hattori, K,, Yoshino, C., Hayakawa, M. and Isezaji, N. (2005) Principal Component Analysis and Singular Spectrum Analysis of ULF Geomagnetic Data Associated with Earthquakes. Natural Hazards and Earth System Sciences, 5, 685-689. https://doi.org/10.5194/nhess-5-685-2005

[16] Li, Q., Zhu, P., Mamatemin, A. and Xu, X. (2011) Detection of ULF Electromagnetic Emission as a Precursors to Two Earthquakes in China. Earthquake Science, 24, 601-607. https://doi.org/10.1007/s11589-011-0822-2

[17] Gotoh, K., Hayakawa, M. and Smirnova, N. (2003) Fractal Analysis of the ULF Geomagnetic Data Obtained at Izu Peninsula, Japan in Relation to Nearby Earthquake Swarm of June-August 2000. Natural Hazards and Earth System Sciences, 3, 229-236. https://doi.org/10.5194/nhess-3-229-2003

[18] Telesca, L., Lapenna, V., Macchiato, M. and Hattori, K. (2008) Investigating Non-Uniform Scaling Behavior in Ultra Low Frequency (ULF) Earthquake-Related Geomagnetic Signal. Earth and Planetary Science Letters, 268, 219-224. https://doi.org/10.1016/j.epsl.2008.01.033

[19] Ding, J.H., Lu, Z.Y. and Huang, X.X. (1994) Seismo-Electromagnetism. Seismological Press, Beijing.

[20] Ding, J.H., Yu, S.R. and Wang, Y.L. (2008) Geomagnetic Low-Point Displacement Phenomena and Strong Earthquake Prediction Research. Chinese Journal of Radio Science, 23, 1011-1017.

[21] Yuan, G.P., Zhang, X.M., Wu, Y.Y. and Zhao, X.D. (2015) Minimum Point Shift of the Geomagnetic Vertical Component in Diurnal Variation and the Internal-External Equivalent Current System $\mathrm{S}_{\mathrm{q}}$ before the 2008 Wenchuan $\mathrm{M}_{\mathrm{s}} 8.0$ Earthquake. Earthquake, 35, 102-112.

[22] Feng, Z.S., Mei, W.P. and Zhang, X.X. (2004) Preliminary Study on the Characteristics of Long and Medium Term Variation for the Amplitude Ratio of Geomagnetic Humorous Wave before Moderate-Strong Earthquakes. Northwestern Seismological Journal, 26, 50-55.

[23] Feng, Z.S., Ju, H.H., Li, H.Y., Zhang, X.X., Yang, C.J. and Li, J.Z. (2009) Further Study on Characteristics of Long-Term and Medium Term Variation of Geomagnetic Harmonic Wave Amplitude Ratios before Moderate or Strong Earthquakes. South China Journal of Seismology, 29, 17-23.

[24] Feng, Z.S., Li, H.Y., Zhang, X.X., Mei, W.P. and Ye, B.W. (2013) The Relationship between Strong Earthquake and Geomagnetic Harmonic Wave Amplitude Ratio. South China Journal of Seismology, 33, 9-15.

[25] Jiang, Y.L., Yuan, G.P., Li, H.Y., Tang, Y.M. and Zhao, W.H. (2016) The Preliminary Analysis on the Characteristics of Geomagnetic Harmonic Wave Amplitude Ratios before the Gaoyou-Baoying $\mathrm{M}_{\mathrm{s}} 4.9$ Earthquake. Earthquake Research in Chi- 
na, 32, 143-150.

[26] Li, Q., Yuan, Y.R., Yang, X., Cai, S.P. and Sun, W.H. (2016) Variation of the Geomagnetic Harmonic Wave Amplitude Ratio before the $\mathrm{M}_{\mathrm{s}} 5.5$ Eryuan Earthquake in 2013. Acta Seismologica Sinica, 38, 122-129.

[27] Dai, Y., Gao, L.X. and Zhang, L.F. (2016) Study on the Amplitude Ratio Geomagnetic Harmonic Wave in Gansu-Qinghai Region. China Earthquake Engineering Journal, 38, 12-25.

[28] Ni, X.Y. and Chen, Y. (2016) The Relationship between Strong Earthquakes in Taiwan and Geomagnetic Harmonic Wave Amplitude Ratio Anomaly in Fujian. South China Journal of Seismology, 36, 56-60.

[29] Bai, Z.M. and Wang, C.Y. (2003) Structure of the Upper Crust and Tomography of Seismic Tectonic Condition in Yunnan. Acta Seismologica Sinica, 25, 117-127.

[30] Mao, Y.P. and Han, X.M. (2003) The Research of Strong Earthquakes $(M \geq 6)$ in Yunan. Yuannan Science Technology Press, Kunming.

[31] Wen, Y.X. (2003) Geomagnetism. Seismological Press, Beijing.

[32] Gong, S.J., Chen, H.R., Zhang, C.F., Yang, C.J. and Ma, S.Q. (1997) The Anomalous Reactions of the Geomagnetic Horizontal Field Transfer Function before Tangshan Earthquake. Acta Seismologica Sinica, 10, 61-70.

https://doi.org/10.1007/s11589-997-0040-0

[33] Park, S.K. (1991) Monitoring Resistivity Changes Prior to Earthquakes in Parkfield, California, with Telluric Arrays. Journal of Geophysical Research, 96, 14211-14237. https://doi.org/10.1029/91JB01228

[34] Du, X.B., Xue, S.Z., Hao, Z. and Zhang, S.Z. (2000) On the Relation of Moderate-Short Term Anomaly of Earth Resistivity to Earthquake. Acta Seismologica Sinica, 22, 368-376. https://doi.org/10.1007/s11589-000-0021-Z

[35] Du, X.B., Ma, Z.H., Ye, Q., Tan, D.C. and Chen, J.Y. (2006) Anisotropic Changes in Apparent Resistivity Associated with Strong Earthquakes. Process in Geophysics, 21, 93-100.

[36] Zheng, G.L., Du, X.B., Chen, J.Y., Tan, D.C., An, Z.H., Fan, Y.Y., Liu, J. and Xie, T. (2011) Influence of Active Faults on Earthquake-Related Anomalies of Geo-Electric Resistivity. Acta Seismologica Sinica, 33, 187-197.

[37] Zhu, T. (2013) Preliminary Study on Regional Geo-Resistivity Anomaly before the Wenchuan $\mathrm{M}_{\mathrm{s}} 8.0$ Earthquakes. Acta Seismologica Sinica, 35, 18-25. 